\title{
PENGARUH BUDAYA ORGANISASI, QUALITY OF WORK LIFE DAN KEPEMIMPINAN TRANSFORMASIONAL TERHADAP KINERJA KARYAWAN
}

\author{
Ni Putu Pratiwi Irmayanthi ${ }^{1}$ \\ Ida Bagus Ketut Surya ${ }^{2}$ \\ ${ }^{1,2}$ Fakultas Ekonomi dan Bisnis Universitas Udayana (Unud), Bali, Indonesia \\ email: irmayanthipratiwi@gmail.com
}

\begin{abstract}
ABSTRAK
Tujuan penelitian ini adalah untuk mengetahui pengaruh budaya organisasi, quality of work life dan kepemimpinan transformasional terhadap kinerja karyawan PT. Harum Indah Sari (HIS) Tours \& Travel Bali. Penelitian ini dilakukan di PT. Harum Indah Sari (HIS) Tours \& Travel Bali dengan jumlah sampel yang digunakan sebanyak 93 karyawan, dengan menggunakan metode sampel jenuh. Pengumpulan data dilakukan melalui wawancara serta penyebaran kuisioner. Teknik analisis data yang digunakan adalah Analisis Regresi Linier Berganda dan Uji Asumsi Klasik. Hasil penelitian ini menunjukkan bahwa budaya organisasi berpengaruh positif dan signifikan terhadap kinerja karyawan, quality of work life berpengaruh positif dan signifikan terhadap kinerja karyawan dan kepemimpinan transformasional berpengaruh positif dan signifikan terhadap kinerja karyawan. Implikasi dari hasil penelitian ini secara teoritis memberikan pemahaman bahwa Budaya organisasi, quality of work life dan Kepemimpinan transformasional secara nyata dapat meningkatkan kinerja karyawan.
\end{abstract}

Kata Kunci: budaya organisasi, quality of work life, kepemimpinan transformasional, kinerja karyawan

\begin{abstract}
The purpose of this study was to determine the effect of organizational culture, quality of work life and transformational leadership on the performance of employees of PT. Harum Indah Sari (HIS) Bali Tours \& Travel. This research was conducted at PT. Harum Indah Sari (HIS) Bali Tours \& Travel with a total sample of 93 employees, using the saturated sample method. Data collection was carried out through interviews and questionnaires. Data analysis techniques used are Multiple Linear Regression Analysis and Classical Assumption Test. The results of this study indicate that organizational culture has a positive and significant effect on employee performance, quality of work life has a positive and significant effect on employee performance and transformational leadership has a positive and significant effect on employee performance. The implications of the results of this study theoretically provide an understanding that organizational culture, quality of work life and transformational leadership can significantly improve employee performance.

Keywords: organizational culture, quality of work life, transformational leadership, employee performance
\end{abstract}




\section{PENDAHULUAN}

Keberadaan sumber daya manusia yang handal memiliki peranan yang strategis dan menjadi salah satu faktor kunci dalam menyambung rantai kesuksesan sebuah organisasi untuk meraih visi atau pun target yang telah ditentukan. Demi tercapainya tujuan-tujuan perusahaan, maka diperlukan sumber daya manusia yang profesional dan memiliki dedikasi tinggi terhadap organisasi, yang kemudian akan memberikan kontribusi positif terhadap organisasi

Salah satu sasaran di dalam pengelolaan manajemen sumber daya manusia adalah diterapkan budaya organisasi, diperhatikan kualitas kehidupan kerja para karyawan serta hubungan antara pemimpin dan karyawan sehingga karyawan mampu untuk mempertahankan serta meningkatkan kinerja di dalam suatu perusahaan. Kinerja seseorang yang baik dapat dilihat dari hasil kerjanya yang telah sesuai dengan standar kinerja organisasi dan dapat mencapai tujuan organisasi atau perusahaan tersebut (Darmasaputra dan Sudibya, 2019).

Keberhasilan perusahaan tergantung pada bagaimana kinerja pegawai, efisiensi, kejujuran, ketekunan dan integritas (Ahmed dan Uddin, 2012). Zameer et al., (2014) menyatakan untuk mencapai kinerja yang baik maka sumber daya manusia dituntut untuk memiliki pengetahuan,ketrampilan, kemampuan, mempunyai pengalaman,motivasi kerja,disiplin kerja, dan semangat kerja yang tinggi sehingga peningkatan kinerja karyawan pada perusahaan tersebut akan berdampak pada kinerja perusahaan yang dapat meningkat, dan pada akhirnya tujuan perusahaan tercapai. Gupta (2013) menjelaskan bahwa perusahaan membutuhkan karyawan yang mampu bekerja lebih baik dan lebih cepat, sehingga diperlukannya karyawan yang mempunyai kinerja (job performance) yang tinggi. Sehingga kinerja yang efektif dan efisien, perusahaan harus mampu mengelola sumber daya manusia dengan baik serta mempertahankan kinerja karyawan terbaiknya yang memiliki komitmen yang tinggi terhadap perusahaan.

Penelitian ini dilakukan di PT Harum Indah Sari Tours \& Travel Bali yang merupakan anak perusahaan dari HIS Co.L.td Jepang. HIS Tours \&Travel beroperasi dalam bidang pariwisata khusunya tour and travel. Perusahaan ini telah membuka banyak cabang di Indonesia dan salah satu cabang yang terletak di Denpasar merupakan Head Office untuk anak perusahaan yang berada di Indonesia. PT.Harum Indah Sari (HIS) Tours \& Travel Bali pada saat ini menjalin kerjasama dengan PT.Bank Negara Indonesia (Persero) Tbk untuk meningkatkan jumlah kunjungan wisatawan ke masing - masing Negara.

Berdasarkan hasil pra-riset dengan metode wawancara dengan pihak HRD terungkap kinerja karyawan PT. Harum Indah Sari (HIS) Tours \& Travel Bali belum maksimal. Kondisi ini dapat dilihat dari beberapa karyawan tidak dapat menyelesaikan tugasnya tepat waktu sesuai dengan target yang telah ditetapkan, serta beberapa karyawan masih sering datang terlambat ke kantor dan dalam menyelesaikan pekerjaan menunggu perintah dari pemimpin. Oleh karena itu, perusahaan harus memperhatikan 
karyawannya, sebab jika kinerja karyawan menurun dapat mempengaruhi kelangsungan hidup dan target dari perusahaan.

Budaya organisasi mengacu pada pola asumsi dasar bersama atau kelompok yang dapat memecahkan masalah yang diadopsi dari eksternal dan integrasi internal yang telah bekerja dengan cukup baik untuk dapat dipertimbangkan (Miharty, 2013). Budaya organisasi merupakan salah satu strategi untuk memotivasi karyawan untuk mencapai kinerja yang maksimal, karena budaya organisasi yang baik dengan sendirinya akan memberikan suatu kondisi yang sesuai dengan perilaku karyawan dalam bekerja apabila budaya tersebut sangat cocok dan mendukung karyawan dalam mengembangkan kemampuan dan menopang kesejahteraannya dengan kata lain, budaya organisasi menjadi faktor penting untuk meningkatkan kinerja karyawan dalam perusahaan (Sagita et al.,2018) .

Menurut Maith (2015) budaya organisasi membuat suatu perusahaan untuk berhasil dan menjadi lebih stabil,lebih maju, lebih antisipatif terhadap perubahan lingkungan. Oleh karena itu, organisasi harus mampu mengajak karyawan untuk melakukan penyesuaian terhadap budaya organisasi yang menjadi pedoman dalam pencapaian tujuan sebuah organisasi (Sutrisno, 2011:39)

Matei (2015) menyatakan bahwa terdapat pengaruh positif antara budaya organisasi dan kinerja karyawan. Budaya organisasi yang terlihat nyata dan kuat dalam suatu perusahaan maka akan berdampak pada karyawan dalam motivasinya untuk menyelesaikan suatu pekerjaan.

Demikian halnya pada budaya organisasi yang ada pada perusahaan yang bergerak di bidang pelayanan jasa ini sudah terbentuk suatu budaya organisasi .PT. Harum Indah Sari Tours \& Travel memiliki budaya organisasi tersendiri, yaitu monthly report. Monthly report merupakan kegiatan pembuatan laporan bulanan dari masing-masing departemen bagian. Selain itu, budaya organisasi yang diterapkan oleh PT Harum Indah Sari Tours \& Travel Bali yaitu penetapan jam kerja yang telah menjadi peraturan tetap, yakni selama 8 jam kerja.

Permasalahan yang berkaitan dengan budaya organisasi pada PT. Harum Indah Sari (HIS) Tours \& Travel Bali yaitu, masih terdapat karyawan yang tidak bisa menyelesaikan monthly report dengan tepat waktu atau terlambat dari waktu yang telah ditetapkan oleh pemimpin, selain itu karyawan mengeluhkan jam kerja yang melebihi dari jam bekerja seharusnya yaitu 8 jam kerja.

Nanjundeswawary (2013) menyatakan bahwa quality of work life adalah kualitas hubungan antara karyawan dan lingkungan kerja. Suasana kerja yang positif akan menciptakan kualitas kehidupan kerja yang kondusif bagi tercapainya tujuan organisasi. Kondisi ini didasarkan bahwa quality of work life seseorang berhubungan dengan perilaku manajemen perusahaan, baik didalam maupun diluar pekerjaan. Usaha peningkatan kualitas kehidupan kerja seorang karyawan dapat memberikan positive feeling yang meluas, dan akhirnya akan berdampak terhadap peningkatan kinerja karyawan (Irawati, 2015) 
Dengan memperhatikan kualitas kehidupan kerja karyawan merupakan salah satu upaya yang dapat dilakukan perusahaan untuk memenuhi kebutuhan karyawan (Santhi, 2016). Dalam penelitian Pasaribu dan Indrawati, (2016) terdapat pengaruh yang positif dan signifikan antara kualitas kehidupan kerja terhadap kinerja karyawan, kualitas kehidupan kerja merupakan konsep yang luas mencakup kondisi kerja yang nyaman dan aman serta memungkinkan pegawai untuk mengembangkan keterampilan dalam bekerja.

Permasalahan yang meliputi quality of work life di PT. Harum Indah Sari (HIS) Tours \& Travel yaitu, suasana kerja yang kurang kondusif sehingga menghambat tujuan dari perusahaan serta hubungan karyawan bekerja sama dalam satu tim yang masih kurang saat menyelesaikan tugas yang diberikan oleh pimpinan, Hal ini dapat berdampak pada kelangsungan hidup perusahaan karena ketika semangat kerja dan kinerja karyawan menurun maka target yang dicapai oleh perusahaan tidak akan optimal.

Faktor penting lain yang berkaitan dengan kinerja adalah gaya kepemimpinan, kepemimpinan yang baik akan memberi target dalam setiap kebijakan, memberikan seluas-luasnya pengembangan karir terhadap pegawai, sehingga setiap kerja keras yang dilakukan pegawai akan selalu diperhatikan, tidak luput juga memberikan lingkungan kerja yang baik dan kondusif bagi pegawai agar tetap nyaman saat bekerja. Banyaknya target yang mesti di raih jika diimbangi dengan hal-hal tersebut bisa memulikan kembali kinerja pegawai (Adinata, 2015)

Caroline (2014) menyatakan bahwa seorang pimpinan yang mengharapkan pencapaian kinerja maksimal pada organisasinya harus memperhatikan faktor-faktor yang mempengaruhi kinerja pegawai itu sendiri. Pemimpin merupakan bagian dari budaya organisasi, tetapi seorang pemimpin juga memiliki kemungkinan untuk bertindak sebagai agen perubahan dalam budaya (Pors, 2008)

Kepemimpinan transformasional dapat membawa keadaan menuju kinerja tinggi pada organisasi yang menghadapi tuntutan pembaharuan dan perubahan..Pemimpin yang menerapkan kepemimpinan transformasional memberikan pengaruh kepada para pengikutnya untuk berpartisipasi dalam pencapaian tujuan, pemecahan masalah dan pengambilan keputusan (Rahmi, 2014). Northhouse (2013:176) menyatakan bahwa kepemimpinan transformasional adalah gaya kepemimpinan yang menekankan pada proses dimana orang terlibat dengan orang lain dan menciptakan suatu hubungan yang meningkatkan motivasi baik dalam diri pemimpin maupun pengikutnya. Anteja (2014) menyatakan bahwa kepemimpinan transformasional berpengaruh positif dan signifikan terhadap semangat dan kinerja karyawan.

Terdapat permasalahan yang berkaitan dengan kepemimpinan transformasional di PT. Harum Indah Sari (HIS) Tours \& Travel Bali, berdasarkan hasil wawancara terhadap 15 karyawan diduga pimpinan perusahaan kurang mampu untuk memberikan motivasi terhadap bawahan dan memberikan acuan terhadap karyawannya untuk bekerja lebih baik lagi, serta membangkitkan suasana dalam bekerja. 
(Hardinaya et al., (2013) dan Cancerina (2013) membuktikan bahwa budaya organisasi berpengaruh signifikan terhadap kinerja. Budaya organisasi yang kuat membantu kinerja organisasi karena memberikan struktur dan kontrol yang dibutuhkan tanpa harus bersandar pada birokrasi formal yang kaku dan yang dapat menekan tumbuhnya motivasi dan inovasi. Ibrahim dan Ahmed (2013) di dalam penelitiannya menyatakan bahwa terdapat korelasi yang positif dan signifikan antara budaya organisasi dengan kinerja karyawan.

Penelitian Gultom (2014) menyatakan jika budaya organisasi memiliki pengaruh yang signifikan terhadap kinerja. Semakin tinggi pengaruh Budaya Organisasi terhadap kinerja karyawan karena adanya penerapan tata kelola perusahaan yang baik dengan budaya perusahaan yang berlandaskan pada asas PROCISE (Professionalism, Continous Improvement, Integrity, safety, Excellent Service). Penelitian Wanjiku \& Lumwagi (2014) menyatakan budaya organisasi berpengaruh positif dan signifikan terhadap kinerja karyawan, artinya budaya organisasi yang tinggi dapat meningkatkan kinerja karyawan Hasil penelitian Adinata (2015) dan Matei (2015) menyatakan bahwa terdapat pengaruh positif antara budaya organisasi dan kinerja karyawan. Budaya organisasi yang terlihat nyata dan kuat dalam suatu perusahaan maka akan berdampak pada karyawan dalam motivasinya untuk menyelesaikan suatu pekerjaan.Penelitan selanjutnya dilakukan oleh Irwan (2018) menyatakan bahwa budaya organisasi berpengaruh positif terhadap kinerja. Hasil penelitian Sinaga et al., (2018) menyatakan bahwa budaya organisasi berpengaruh positif dan signifikan terhadap kinerja pegawai.

$\mathrm{H}_{1:}$ Budaya Organisasi Berpengaruh Positif dan Signifikan terhadap Kinerja Karyawan

Hasil penelitian Irawati (2015) menyatakan bahwa quality of work life memiliki pengaruh positif dan signifikan terhadap kinerja pegawai. Penelitian selanjutnya yang dilakukan oleh Rai dan Tripathi (2015) menyatakan quality of work life berpengaruh positif terhadap kinerja. Penelitian yang dilakukan oleh Chanana dan Gupta (2016) menyatakan bahwa quality of work life berpengaruh positif dan signifikan terhadap kinerja pegawai. Didukung oleh penelitian Pasaribu dan Pasaribu dan Indrawati (2016) bahwa terdapat pengaruh yang positif dan signifikan antara kualitas kehidupan kerja (Quality of work life) terhadap kinerja karyawan Dinas Sosial Provinsi Bali, Dengan meningkatnya kualitas kehidupan kerja di organisasi akan mempengaruhi pula peningkatan kinerja pegawai, sehingga dapat menciptakan pelayanan yang optimal kepada masyarakat. Hasil penelitian Rahmawati (2017) menyatakan jika quality of work life berpengaruh positif dan signifikan terhadap kinerja pegawai. Penelitan selanjutnya dilakukan oleh (Bindi dan Dharmaraj (2017) menyatakan bahwa quality of work life berpengaruh positif terhadap kinerja. Hail penelitian Sinaga et al., (2018) menyatakan bahwa quality of work life berpengaruh positif dan signifikan terhadap kinerja pegawai.

$\mathrm{H}_{2}$ : Quality of Work Life Berpengaruh Positif dan Signifikan terhadap Kinerja Karyawan 
Penelitian oleh Khan et al., (2012) menyatakan bahwa kepemimpinan transformasional lebih fleksibel meningkatkan kreativitas karyawan dan otonomi oleh karena itu kinerja karyawan meningkat. Hasil penelitian Bo (2013) menyatakan bahwa kepemimpinan transformasional memiliki pengaruh positif dan signifikan terhadap kinerja pegawai.

Pradana (2013) bahwa kepemimpinan transformasional secara parsial memiliki pengaruh yang signifikan terhadap kinerja karyawan. Hasil penelitian ini mendukung penelitian terdahulu yang dilakukan oleh Rolasmana (2013) bahwa gaya kepemimpinan berpengaruh signifikan terhadap kinerja karyawan

Penelitian selanjutnya yang dilakukan oleh Caillier, (2014) menyatakan kepemimpinan transformasional berpengaruh positif terhadap kinerja. Penelitian yang dilakukan oleh Adinata (2015) menyatakan bahwa kepemimpinan transformasional berpengaruh positif dan signifikan terhadap kinerja pegawai. Putri dan Iskandar (2016) membuktikan bahwa kepemimpinan transformasional berpengaruh secara positif dan signifikan terhadap kinerja karyawan.

Hasil penelitian Septyan et al. (2017) menyatakan jika kepemimpinan transformasional berpengaruh positif dan signifikan terhadap kinerja pegawai.

$\mathrm{H}_{3}$ : Kepemimpinan Transformasional Berpengaruh Positif dan Signifikan terhadap Kinerja Karyawan

Teori yang melandasi penelitian ini adalah Teori Pertukaran Sosial (Social Exchange Theory) yang menggambarkan berbagai transaksi yang terjadi di seluruh kehidupan sosial seseorang yang ditandai dengan hubungan emosional yang kuat. Menurut Jia et al., (2014) teori pertukaran sosial merupakan teori yang meneliti tentang pengaruh hubungan antara organisasi dengan karyawan. Pertukaran dapat terjadi apabila antara karyawan dan organisasi mampu memberikan Sesuatu hal satu sama lain yang didasari pada kepercayaan Aswin dan Rahyuda (2017).

Fung, et al. (2012) menyatakan bahwa teori pertukaran sosial adalah karyawan yang telah diperlakukan dengan baik oleh organisasi, maka mereka akan memberikan timbal balik yang positif terhadap organisasi. Menggunakan teori ini untuk berpendapat bahwa, ketika seseorang merasa puas dalam organisasi, maka mereka akan membalasnya dan meningkatkan kinerja. Serim et al., (2014) mengemukakan bahwa hubungan di tempat kerja memiliki unsur-unsur dari teori pertukaran sosial. Teori pertukaran sosial mendominasi ciri kepribadian dan sikap seseorang. Teori pertukaran sosial menjelaskan hubungan antara seseorang dan organisasi, terutama antara karyawan dengan perusahaan, ataupun perusahaan dengan karyawannya Zeinabadi dan Keyvan (2011). Menurut teori pertukaran sosial karyawan perlu mendukung organisasi mereka dengan menunjukkan lebih banyak usaha dan sikap yang positif Cropanzano dan Mitchell (2005).

Seseorang akan mengembangkan tingkat saling mendukung yang kuat dengan organisasi atau pimpinan mereka, dan dapat menyebabkan perilaku 
kerja yang efektif, seperti kinerja yang lebih baik dan lebih banyak memberikan bantuan untuk rekan kerja Cheung (2013).

Kinerja atau job performance merupakan tingkat keberhasilan karyawan dalam menyelesaikan pekerjaan mereka (Gupta dan Sharma, 2016). Sutanto dan Kurniawan (2016) mengemukakan bahwa kinerja bukan karakteristik individu, seperti bakat atau kemampuan, tetapi manifestasi dari kemampuan dalam bentuk karya nyata atau merupakan karya yang diraih oleh karyawan dalam menjalankan tugas dan pekerjaan yang berasal dari perusahaan.

Kinerja adalah sejauh mana seseorang telah menerapkan strategi perusahaan, baik dalam mencapai tujuan spesifik terkait dengan peran individu atau dengan menunjukkan kompetensi yang dinyatakan relevan dengan perusahaan Harwiki, (2016). Kinerja adalah konsep multidimensi yang mencakup tiga aspek, yaitu sikap, kemampuan, dan prestasi. Kinerja pada dasarnya adalah apa yang karyawan lakukan atau tidak lakukan Bin Shmailan (2016).

Sinaga et al. (2018) mengemukakan bahwa kinerja adalah perwujudan dari pekerjaan yang telah diproduksi atau dijalankan oleh karyawan. Kinerja pegawai memainkan peran penting pada suatu organisasi. Kinerja setiap pegawai merupakan sumbangan bagi tercapainya kinerja setiap fungsi organisasi, bila kinerja yang diperlihatkan oleh para pegawai rendah, maka tujuan organisasi menjadi terhambat Widodo (2014).

Kinerja karyawan merupakan hasil kerja yang dicapai seseorang dalam melaksanakan tugas-tugas yang dibebankan kepadanya untuk mencapai target kerja (Fariz et al., 2017). Kinerja adalah hasil dari proses yang mengacu dan diukur selama periode waktu tertentu berdasarkan ketentuan atau kesepakatan yang telah ditetapkan sebelumnya (Emron dkk., 2016:188) Dewi dan Utama (2016) kinerja merupakan hasil kerja yang dihasilkan baik dari segi kualitas maupun kuantitas pekerjaannya dan dapat dipertanggungjawabkan sesuai dengan perannya didalam organisasi atau perusahaan, dan disertai dengan kemampuan, kecakapan, dan keterampilan dalam menyelesaikan pekerjaannya dan dalam periode tertentu.

Tinofirei (2011) menyatakan kinerja merupakan hasil kerja dalam periode tertentu yaitu kualitas dan kuantitas yang dihasilkan oleh seorang karyawan sesuai dengan tanggung jawab yang telah diberikan.

Kinerja berdasarkan beberapa sumber diatas, dapat dinyatakan sebagai hasil kerja yang dilakukan oleh seseorang dalam organisasi agar tercapai tujuan yang diiginkan suatu organisasi.

Budaya organisasi adalah nilai dan norma yang mengatur perilaku anggota kelompok yang menyiratkan apa yang penting atau ditegakkan oleh organisasi atau upaya organisasi untuk mengatur perilaku yang diharapkan dari para anggotanya. Dengan pandangan ini, budaya organisasi relatif dari satu organisasi ke organisasi lain, tergantung pada nilai dan norma yang dikembangkan Harwiki (2016). Griffen dan Ebbert dalam Adinata (2015) mengungkapkan bahwa budaya organisasi bisa diartikan sebagai pengalaman, 
sejarah, keyakinan dan norma-norma bersama yang menjadi ciri perusahaan atau organisasi.

Arifin (2015) menyatakan bahwa budaya organisasi adalah semua keyakinan,perasaan,perilaku dan simbol-simbol yang mencirikan suatu organisasi.Budaya organisasi merupakan suatu kepercayaan dan prinsip etika dari anggota organisasi yang memainkan peran penting dalam sistem manajemen organisasi (Ramezan, 2016). Irwan (2018) menyatakan bahwa budaya organisasi adalah persepsi yang dimiliki oleh anggota organisasi lain. Sebuah aturan atau kewajiban yang harus dipenuhi oleh karyawan jika sudah diubah menjadi budaya, itu akan memudahkan manajemen dalam mengelola karyawan yang ada dengan tindakan peringatan minimum untuk para karyawan

Budaya organisasi adalah keyakinan dan nilai bersama yang memberikan makna bagi anggota sebuah institusi dan menjadikan keyakinan dan nilai tersebut sebagai aturan atau pedoman berperilaku di dalam organisasi (Sobirin, 2007) Budaya organisasi dapat menjadi sarana untuk menjaga agar karyawan tetap sejalan dan menyesuaikannya dengan tujuan organisasi (Omotayo,2013). Belias dan Koustelios, (2014) mengemukakan bahwa budaya organisasi adalah suatu pemikiran yang mendasar untuk memecahkan suatu masalah baik masalah secara internal maupun eksternal organisasi.

Berdasarkan beberapa sumber diatas budaya organisasi dapat dinyatakan sebagai prinsip atau karakteristik yang ada di dalam suatu organisasi dan menjadi pedoman bagi para anggota organisasi.

Quality of work life adalah jumlah total nilai baik material maupun non material, yang diperoleh oleh seorang karyawan sepanjang masa jabatannya di organisasi dalam pertukaran usahanya dikaitkan dengan pencapaian tujuan organisasi (Malini et al., 2012) Kualitas kehidupan kerja atau quality of work life adalah proses organisasi kerja, yang memungkinkan anggotanya di semua tingkatan untuk berpartisipasi aktif dalam membentuk organisasi, lingkungan, metode, dan hasil (Chanana dan Gupta, 2016).

Kurniasari dan Himam (2014) menyatakan bahwa quality of work life adalah tingkatan dimana individu mendapat kepuasan dalam pemenuhan kebutuhan personal, seperti kebutuhan akan kebebasan ketika bekerja dalam organisasi. Irawati (2015) menyatakan bahwa quality of work life merupakan istilah umum yang meliputi perasaan seseorang yang berhubungan dengan setiap dimensi kesejahteraan, upah, keamanan, kondisi kerja organisasi dan hubungan antar karyawan maupun dengan organisasi atau instansi.

Permana et al. (2015) mengemukakan bahwa quality of work life adalah upaya yang dilakukan manajemen terhadap peningkatan mutu karyawan dengan menghargai dan memerhatikan segala faktor kondisi kerja, agar tercipta keselarasan antara pekerjaan dengan berbagai faktor yang memengaruhi pekerjaan tersebut. Kualitas kehidupan kerja merupakan konsep yang luas mencakup kondisi kerja yang nyaman dan aman serta memungkinkan pegawai untuk mengembangkan keterampilan dalam bekerja (Pasaribu dan Indrawati, 2016). 
Berdasarkan beberapa sumber diatas quality of work life dapat dinyatakan sebagai suatu cara pandang organisasi yang bertujuan untuk melakukan peningkatan kualitas kehidupan karyawan.

\section{METODE PENELITIAN}

Lokasi penelitian bertempat di PT. Harum Indah Sari Tours \& Travel, yang beralamat di Jalan By Pass Ngurah Rai No.732, Pesanggaran, Denpasar. Alasan yang melatar belakangi peneliti melakukan penelitian di PT. Harum Indah Sari Tours \& Travel dikarenakan target yang harus dicapai oleh perusahaan untuk meningkatkan profit tahunan maka diperlukan beberapa hal-hal yang terkait dengan variabel dalam meningkatkan kinerja karyawan PT. Harum Indah Sari Tours \& Travel. Selain itu, adanya akses yang memudahkan peneliti untuk mendapatkan informasi yang dibutuhkan dalam penelitian ini.

Populasi dari penelitian ini adalah seluruh karyawan PT. Harum Indah Sari (HIS) Tours \& Travel Bali yang berjumlah 93 orang. Metode yang digunakan dalam penentuan sampel adalah metode nonprobability sampling yang didalamnya terdapat metode sampling jenuh, yaitu dimana semua anggota populasi digunakan sebagai sampel penelitian. Sampel dalam penelitian ini adalah seluruh karyawan PT. Harum Indah Sari (HIS) Tours \& Travel Bali yang berjumlah 93 orang.

Metode regresi linier berganda digunakan dalam penelitian ini untuk mengetahui pengaruh Budaya Organisasi (X1), Quality Of Work Life (X2), Kepemimpinan transformasional (X3) dan Kinerja Karyawan (Y). Dalam analisis peneliti dibantu dengan program SPSS for Windows. Adapun rumus model regresi linier berganda (Nata Wirawan, 2015:257)sebagai berikut.

$$
\begin{array}{ll}
\mathrm{Y}=\alpha+\beta_{1} \mathrm{X}_{1}+\beta_{2} \mathrm{X}_{2}+\beta_{3} \mathrm{X}_{3}+\mathrm{e} \ldots \ldots \ldots \ldots \ldots \ldots \ldots \ldots \ldots \\
\text { Keterangan: } \\
\mathrm{Y} \quad=\text { Kinerja Karyawan } \\
\alpha & =\text { Konstanta } \\
\beta_{1}-\beta_{3} & =\text { Koefisien regresi } \\
\mathrm{X} 1 & =\text { Budaya Organisasi } \\
\mathrm{X} 2 & =\text { Quality of Work Life } \\
\mathrm{X} 3 & =\text { Kepemimpinan Transformasional } \\
\mathrm{e} & =\text { Variabel Pengganggu (residual error) }
\end{array}
$$

\section{HASIL DAN PEMBAHASAN}

Model analisis regresi linear berganda digunakan untuk mendapat koefisien regresi yang akan menentukan apakah hipotesis yang dibuat akan diterima atau ditolak. Hasil analisis ini mengacu pada hasil pengaruh variabel Budaya organisasi $\left(\mathrm{X}_{1}\right)$, variabel Quality Of Work Life $\left(\mathrm{X}_{2}\right)$ variabel Kepemimpinan transformasional $\left(\mathrm{X}_{3}\right)$ terhadap Kinerja karyawan (Y) PT. Harum Indah Sari (HIS) Tours \& Travel Bali Adapun hasil analisis regresi 
dengan program Statitical Pacage of Social Science (SPSS) versi 21.0 for Windows dapat dilihat pada Tabel 1. berikut.

Tabel 1.

Rangkuman Hasil Analisis Regresi Linear Berganda

\begin{tabular}{crcrr}
\hline $\begin{array}{c}\text { Unstandardized Coefficients } \\
\text { B }\end{array}$ & Std. Error & $\begin{array}{c}\text { Standardized Coefficients } \\
\text { Beta }\end{array}$ & t & Sig. \\
\hline 0.241 & 0.262 & & 0.919 & 0.361 \\
0.304 & 0.098 & 0.276 & 3.100 & 0.003 \\
0.411 & 0.094 & 0.412 & 4.367 & 0.000 \\
0.227 & 0.092 & 0.222 & 2.469 & 0.015 \\
\hline
\end{tabular}

Sumber: Data diolah, 2019

Berdasarkan Tabel 1. dapat ditulis persamaan regresi linear berganda sebagai berikut.

Dimana :

$$
\mathrm{Y}=0,241+0,304 \mathrm{X}_{1}+0,411 \mathrm{X}_{2}+0,227 \mathrm{X}_{3}
$$

$\mathrm{Y}=$ Kinerja karyawan

$\mathrm{X}_{1}=$ Budaya organisasi

$\mathrm{X}_{2}=$ Quality Of Work Life

$\mathrm{X}_{3}=$ Kepemimpinan transformasional

Konstanta $(\alpha)$ 0,241 memiliki arti apabila Budaya organisasi, Quality Of Work Life dan Kepemimpinan transformasional bernilai sama dengan 0 (nol) maka Kinerja karyawan PT. Harum Indah Sari (HIS) Tours \& Travel Bali bernilai sebesar 0,241. Koefisien regresi variabel Budaya Organisasi berpengaruh positif terhadap Kinerja karyawan PT. Harum Indah Sari (HIS) Tours \& Travel Bali, apabila budaya organisasi meningkat maka kinerja karyawan akan mengalami peningkatan sebesar 0,304. Koefisien regresi variabel Quality of Work Life berpengaruh positif terhadap Kinerja karyawan PT. Harum Indah Sari (HIS) Tours \& Travel Bali, apabila Quality Of Work Life karyawan meningkat maka kinerja karyawan akan mengalami peningkatan sebesar 0,411. Koefisien regresi variabel Kepemimpinan transformasional berpengaruh positif terhadap Kinerja karyawan PT. Harum Indah Sari (HIS) Tours \& Travel Bali, apabila Kepemimpinan transformasional karyawan meningkat maka Kinerja karyawan akan mengalami peningkatan sebesar 0,227.

Pada penelitian ini pengujian normalitas dilakukan menggunakan analisis statistik One-Sample Kolmogorov-Smirnov, yaitu dengan membandingkan Kolmogorov-Smirnov hitung dengan Kolmogorov-Smirnov tabel. One-Sample Kolmogorov-Smirnov pada uji non parametrik. Adapun hasil uji One-Sample Kolmogorov-Smirnov dapat ditampilkan dalam Tabel 2.

Berdasarkan uji normalitas dengan menggunakan One-Sample Kolmogorov-Smirnov Test yang ditampilkan pada Tabel 2. tersebut menunjukkan bahwa besarnya nilai Kolmogorov-Smirnov adalah sebesar 0,334. Nilai Kolmogorov-Smirnov tersebut lebih besar dibandingkan dengan nilai Kolmogorov-Smirnov tabel sebesar 0,05 maka $\mathrm{H}_{\mathrm{o}}$ diterima yang 
mengindikasikan bahwa data yang digunakan pada penelitian ini terdistribusi normal, sehingga dapat disimpulkan bahwa model memenuhi asumsi normalitas.

Tabel 2.

Uji Normalitas (One-Sample Kolmogorov-Smirnov)

\begin{tabular}{lr}
\hline & Unstandardized Residual \\
\hline $\mathrm{N}$ & 93 \\
Kolmogorov-Smirnov Z & 0,945 \\
Asymp. Sig. (2-tailed) & 0,334 \\
\hline
\end{tabular}

Sumber: Data diolah, 2019

Uji multikolinearitas dilakukan untuk melihat apakah terdapat korelasi yang sempurna antar variabel bebas yang digunakan pada penelitian ini. Pengujian multikolinearitas dilakukan dengan menganalisis nilai tolerance dan nilai VIF. Nilai tolerance dan nilai VIF digunakan untuk mengukur variabilitas variabel independen atau hubungan antar variabel independen, jika nilai tolerance kurang dari 0,10 atau nilai VIF lebih dari 10 maka menunjukkan adanya multikolinearitas. Adapun nilai tolerance dan nilai VIF ditunjukkan pada Tabel 3. berikut:

Tabel 3.

Uji Multikolinieritas (Tolerance dan Variance Inflation Factor)

\begin{tabular}{lcc}
\hline \multicolumn{1}{c}{ Variabel } & \multicolumn{1}{c}{ Collinearity Statistics } & \\
& Tolerance & VIF \\
\hline Budaya organisasi & 0.495 & 2.021 \\
Quality Of Work Life & 0.440 & 2.270 \\
Kepemimpinan transformasional & 0.485 & 2.061 \\
\hline Sumber: Data diolah, 2019 & &
\end{tabular}

Berdasarkan Tabel 3. tersebut ditunjukkan bahwa tidak terdapat variabel bebas yang memiliki nilai tolerance kurang dari 0,10 dan juga tidak ada variabel bebas yang memiliki nilai VIF lebih dari 10. Maka dari pada itu model regresi bebas dari gejala multikoleniaritas.

Pengujian heteroskedastisitas diakukan melalui metode glesjer dan dengan grafik scatterplot. Metode glesjer meregresikan model regresi untuk mendapatkan nilai residualnya, kemudian nilai residual tersebut diabsolutkan dan dilakukan regresi dengan semua variabel independen. Bila terdapat variabel independen yang berpengaruh secara signifikan terhadap residual absolut maka terjadi heteroskedastisitas pada model regresi ini.Tabel 4 . menunjukkan hasil perhitungan statistik dengan metode glesjer.

Berdasarkan Tabel 4. tersebut, ditunjukkan bahwa masing-masing model memiliki nilai signifikansi lebih besar dari 5\%. Hal ini menunjukkan bahwa variabel bebas yang digunakan pada penelitian ini tidak berpengaruh secara signifikan terhadap variabel terikatnya yaitu absolute error, maka dari itu, penelitian ini bebas dari gejala heteroskedastisitas. 
Tabel 4 .

Uji Heteroskedastisitas (Uji Glesjer)

\begin{tabular}{lrrrrr}
\hline \multicolumn{1}{c}{ Variabel } & \multicolumn{2}{c}{$\begin{array}{c}\text { Unstandardized } \\
\text { Coefficients }\end{array}$} & $\begin{array}{c}\text { Standardized } \\
\text { Coefficients } \\
\text { Beta }\end{array}$ & t & Sig. \\
& B & Std. Error & \multicolumn{1}{c}{. } & \\
\hline (Constant) & 0.548 & 0.172 & & 3.181 & 0.002 \\
Budaya organisasi & -0.003 & 0.064 & -0.008 & -0.053 & 0.958 \\
Quality Of Work Life & -0.040 & 0.062 & -0.103 & -0.645 & 0.520 \\
Kepemimpinan & 0.015 & 0.060 & 0.039 & 0.254 & 0.800 \\
transformasional & 0.015 & & & &
\end{tabular}

Sumber: Data diolah, 2019

Nilai koefisien determinasi adalah 0 (nol) atau 1 (satu). Nilai Adjusted $R$ Square yang kecil berarti kemampuan variabel-variabel bebas dalam menjelaskan variasi variabel terikat sangat terbatas. Nilai yang mendekati 1 berarti variabel-variabel bebas memberikan hampir semua informasi yang dibutuhkan untuk memprediksi variasi variabel terikat

Tabel 5.

Analisis Determinasi

\begin{tabular}{lcccc}
\hline Model & R & R Square & Adjusted R Square & $\begin{array}{c}\text { Std. Error of the } \\
\text { Estimate }\end{array}$ \\
\hline 1 & $0.806^{\mathrm{a}}$ & 0.650 & 0.638 & 0.61755 \\
\hline Sumber: Data diolah, 2019 & & &
\end{tabular}

Berdasarkan Tabel 5 dapat diamati nilai adjusted $\mathrm{R}^{2}$ sebesar 0,650 Adapun analisis menggunakan rumus sebagai berikut:

$$
\begin{aligned}
& D=r^{2} \times 100 \% \ldots \ldots \\
& D=0,650 \times 100 \% \\
& D=65 \%
\end{aligned}
$$

Berdasarkan hasil tersebut diketahui bahwa nilai $\mathrm{R}^{2}=65$ persen, yang berarti bahwa sebesar 65 persen Kinerja karyawan PT. Harum Indah Sari (HIS) Tours \& Travel Bali dipengaruhi oleh variabel Budaya organisasi (X1), Quality Of Work Life (X2), dan Kepemimpinan transformasional (X3) dan sisanya sebesar 35 persen dipengaruhi oleh variabel lain yang tidak diteliti pada penelitian ini.

Uji F digunakan untuk mengetahui apakah secara serempak (simultan) seluruh variabel bebas (variabel Budaya organisasi, variabel Quality Of Work Life variabel Kepemimpinan transformasional) memiliki pengaruh terhadap variabel terikat (Kinerja karyawan). Tabel 6. menunjukkan hasil perhitungan uji F dengan menggunakan SPSS 21.

Tabel 6.

Hasil Uji F

\begin{tabular}{llrrrrr}
\hline Model & & Sum of Squares & df & Mean Square & F & \multicolumn{1}{c}{ Sig. } \\
\hline \multirow{3}{*}{1} & Regression & 63.096 & 3 & 21.032 & 55.148 & $0.000^{\mathrm{b}}$ \\
& Residual & 33.942 & 89 & 0.381 & & \\
& Total & 97.038 & 92 & & & \\
\hline
\end{tabular}

Sumber: Data diolah, 2019 
Adapun langkah-langkah pengujian pengaruh Budaya organisasi yaitu variabel Budaya organisasi $\left(\mathrm{X}_{1}\right)$, variabel Quality Of Work Life $\left(\mathrm{X}_{2}\right)$, variabel Kepemimpinan transformasional $\left(\mathrm{X}_{3}\right)$ terhadap Kinerja karyawan $(\mathrm{Y})$ secara serempak (uji F) adalah sebagai berikut.

Berdasarkan hasil analisis, diketahui nilai signifikansi $\mathrm{F}$ adalah $0,000<$ 0,05 , maka $\mathrm{H}_{0}$ ditolak. Hal ini berarti bahwa variabel Budaya organisasi $\left(\mathrm{X}_{1}\right)$, variabel Quality Of Work Life $\left(\mathrm{X}_{2}\right)$, variabel Kepemimpinan transformasional $\left(\mathrm{X}_{3}\right)$, secara simultan berpengaruh signifikan terhadap kinerja karyawan (Y) PT. Harum Indah Sari (HIS) Tours \& Travel Bali, atau model yang digunakan dalam penelitian layak dan dapat dipergunakan untuk analisis berikutnya.

Uji parsial (uji t) digunakan untuk menguji pengaruh masing-masing variabel bebas (variabel Budaya organisasi, variabel Quality Of Work Life , variabel Kepemimpinan transformasional) terhadap variabel terikat (Kinerja karyawan). Tabel 7. menunjukkan hasil perhitungan uji $t$ dengan menggunakan SPSS 21.

Tabel 7.

Hasil Uji t

\begin{tabular}{lrr}
\hline Variabel & Unstandardized Coefficients Beta & Sig. \\
\hline Budaya organisasi & 0,304 & 0,003 \\
Quality Of Work Life & 0,411 & 0,000 \\
Kepemimpinan transformasional & 0,227 & 0,015 \\
\hline Sumber: Data diolah, 2019 & &
\end{tabular}

Berdasarkan hasil analisis di atas dapat dijelaskan bahwa tingkat signifikansi $0,003<0,05$, sehingga $\mathrm{H}_{0}$ ditolak dan $\mathrm{H}_{\mathrm{a}}$ diterima yang berarti bahwa variabel Budaya organisasi berpengaruh positif signifikan terhadap Kinerja karyawan. Koefisien regresi $\beta 1$ (variabel Budaya organisasi) sebesar 0,304, menunjukkan bahwa meningkatnya Budaya organisasi maka akan meningkatkan Kinerja karyawan PT. Harum Indah Sari (HIS) Tours \& Travel Bali

Berdasarkan hasil analisis di atas dapat dijelaskan bahwa tingkat signifikansi $0,000<0,05$, sehingga $\mathrm{H}_{0}$ ditolak dan $\mathrm{H}_{\mathrm{a}}$ diterima yang berarti bahwa variabel Quality Of Work Life berpengaruh positif signifikan terhadap kinerja karyawan. Koefisien regresi $\beta 2$ (variabel Quality Of Work Life) sebesar 0,411, menunjukkan bahwa meningkatnya Quality Of Work Life maka akan meningkatkan Kinerja karyawan PT. Harum Indah Sari (HIS) Tours \& Travel Bali.

Berdasarkan hasil analisis di atas dapat dijelaskan bahwa tingkat signifikansi $0,015<0,05$, sehingga $\mathrm{H}_{0}$ ditolak dan $\mathrm{H}_{\mathrm{a}}$ diterima yang berarti bahwa variabel Kepemimpinan transformasional berpengaruh positif signifikan terhadap Kinerja karyawan. Koefisien regresi $\beta 3$ (variabel Kepemimpinan transformasional ) sebesar 0,227, menunjukkan bahwa meningkatnya Kepemimpinan transformasional maka akan meningkatkan Kinerja karyawan PT. Harum Indah Sari (HIS) Tours \& Travel Bali.. 
Berdasarkan pengolahan data SPSS dihasilkan tingkat signifikansi $0,003<0,05$. Berdasarkan nilai pengujian tersebut, dapat dilihat dengan statistik bahwa uji jatuh pada penolakan $\mathrm{H}_{0}$ ditolak dan $\mathrm{H}_{1}$ diterima untuk hipotesis pertama. Hal tersebut menyatakan penerimaan hipotesis yang bahwa terdapat pengaruh positif dan signifikan antara Budaya organisasi terhadap Kinerja karyawan PT. Harum Indah Sari (HIS) Tours \& Travel Bali. Koefisien variabel X1 adalah positif 0,304 artinya Budaya organisasi berpengaruh positif terhadap Kinerja karyawan. Apabila Budaya organisasi meningkat sedangkan Quality of Work Life dan Kepemimpinan transformasional tetap, maka Kinerja karyawan akan meningkat sebesar 0,304 . Hasil penelitian ini sesuai dengan penelitian yang dilakukan oleh Hardinaya, et al., (2013) dan Cancerina (2013) membuktikan bahwa budaya organisasi berpengaruh signifikan terhadap kinerja. Budaya organisasi yang kuat membantu kinerja organisasi karena memberikan struktur dan kontrol yang dibutuhkan tanpa harus bersandar pada birokrasi formal yang kaku dan yang dapat menekan tumbuhnya motivasi dan inovasi. Budaya organisasi yang terlihat nyata dan kuat dalam suatu perusahaan maka akan berdampak pada karyawan dalam motivasinya untuk menyelesaikan suatu pekerjaan. Penelitian Ibrahim (2013) mendukung bahwa terdapat korelasi yang positif dan signifikan antara budaya organisasi dengan kinerja karyawan.

Penelitian Gultom (2014) mendukung jika budaya organisasi memiliki pengaruh yang signifikan terhadap kinerja. Penelitian Wanjiku dan Lumwagi, (2014) menguatkan bahwa budaya organisasi berpengaruh positif dan signifikan terhadap kinerja karyawan, artinya budaya organisasi yang tinggi dapat meningkatkan kinerja karyawan Hasil penelitian Adinata (2015), diperluas oleh penelitian selanjutnya yang dilakukan oleh. Irwan (2018) menyatakan bahwa budaya organisasi berpengaruh positif terhadap kinerja karyawan.

Berdasarkan pengolahan data SPSS dihasilkan tingkat signifikansi $0,000<0,05$. Berdasarkan nilai pengujian tersebut, dapat dilihat dengan statistik bahwa uji jatuh pada penolakan $\mathrm{H}_{0}$ ditolak dan $\mathrm{H}_{1}$ diterima untuk hipotesis kedua. Hal tersebut menyatakan penerimaan hipotesis bahwa terdapat pengaruh positif dan signifikan antara quality of work life terhadap kinerja karyawan PT. Harum Indah Sari (HIS) Tours \& Travel Bali .Koefisien variabel X2 adalah positif 0,411, artinya Quality Of Work Life berpengaruh positif terhadap kinerja karyawan. Apabila Quality Of Work Life meningkat sedangkan budaya organisasi dan Kepemimpinan transformasional tetap, maka kinerja karyawan akan meningkat sebesar 0,411 . Hasil penelitian ini sesuai dengan penelitian yang dilakukan oleh penelitian Irawati (2015) menyatakan bahwa quality of work life memiliki pengaruh positif dan signifikan terhadap kinerja pegawai. Penelitian selanjutnya yang dilakukan oleh Rai dan Tripathi (2015) mendukung bahwa quality of work life berpengaruh positif terhadap kinerja karyawan.

Penelitian Chanana dan Gupta (2016) memperluas bahwa quality of work life berpengaruh positif dan signifikan terhadap kinerja karyawan,dengan memperhatikan kualitas kehidupan kerja karyawan dapat 
membuat semua anggota organisasi berpartisipasi aktif dalam membentuk organisasi dan meningkatkan hasil kerja. Pasaribu dan Indrawati (2016) mendukung bahwa terdapat pengaruh yang positif dan signifikan antara kualitas kehidupan kerja (Quality of work life) terhadap kinerja karyawan. Hasil penelitian Rahmawati dan Setiawati (2017) menyatakan jika quality of work life berpengaruh positif dan signifikan terhadap kinerja karyawan. Penelitan selanjutnya dilakukan oleh Bindi dan Dharmaraj (2017) menyatakan bahwa quality of work life berpengaruh positif terhadap kinerja. Hail penelitian Sinaga et al. (2018) menyatakan bahwa quality of work life berpengaruh positif dan signifikan terhadap kinerja pegawai.

Berdasarkan pengolahan data SPSS dihasilkan tingkat signifikansi $0,015<0,05$. Berdasarkan nilai pengujian tersebut, dapat dilihat dengan statistik bahwa uji jatuh pada penolakan $\mathrm{H}_{0}$ ditolak dan $\mathrm{H}_{1}$ diterima untuk hipotesis kedua. Hal tersebut menyatakan penerimaan hipotesis yang bahwa terdapat pengaruh positif dan signifikan antara Kepemimpinan Transformasional terhadap Kinerja karyawan PT. Harum Indah Sari (HIS) Tours \& Travel Bali. Koefisien variabel X3 adalah positif 0,227, artinya Kepemimpinan transformasional berpengaruh positif terhadap Kinerja karyawan. Apabila Kepemimpinan transformasional meningkat sedangkan Budaya organisasi dan Quality Of Work Life tetap, maka Kinerja karyawan akan meningkat sebesar 0,227. Hasil penelitian ini sesuai dengan penelitian yang dilakukan oleh Khan et al. (2012) menyatakan bahwa kepemimpinan transformasional lebih fleksibel meningkatkan kreativitas karyawan dan otonomi oleh karena itu kinerja karyawan meningkat. Hasil penelitian Bo (2013) dan Pradana (2013) mendukung bahwa kepemimpinan transformasional memiliki pengaruh positif dan signifikan terhadap kinerja pegawai. Hasil penelitian ini mendukung dan memperkuat penelitian terdahulu yang dilakukan oleh Rolasmana (2013) bahwa gaya kepemimpinan berpengaruh signifikan terhadap kinerja karyawan. Penelitian selanjutnya yang dilakukan oleh Caillier (2014) menyatakan kepemimpinan transformasional berpengaruh positif terhadap kinerja. Penelitian yang dilakukan oleh Adinata (2015) menyatakan bahwa kepemimpinan transformasional berpengaruh positif dan signifikan terhadap kinerja pegawai. Putri dan Iskandar (2016) membuktikan bahwa kepemimpinan transformasional berpengaruh secara positif dan signifikan terhadap kinerja karyawan. Hasil penelitian Septyan et al. (2017) menyatakan jika kepemimpinan transformasional berpengaruh positif dan signifikan terhadap kinerja pegawai.

Implikasi teoritis dari hasil penelitian ini memberikan bukti pada pengembangan ilmu perilaku keorganisasian dan sumber daya manusia khususnya mengenai Budaya organisasi, Quality Of Work Life, Kepemimpinan transformasional dan kinerja karyawan. Dengan demikian, hasil penelitian ini memberi dukungan empiris dan dapat dinyatakan memperkuat hasil-hasil studi terdahulu. Selain itu hasil penelitian ini secara praktis dapat menjadi salah satu acuan bagi peneliti lainnnya yang ingin meneliti mengenai Budaya organisasi, Quality Of Work Life, Kepemimpinan 
transformasional dan kinerja karyawan. Secara teoritis penelitian ini juga memberikan pemahaman bahwa Budaya organisasi, Quality Of Work Life dan Kepemimpinan transformasional secara nyata dapat meningkatkan kinerja karyawan,dengan meningkatkan Budaya organisasi, Quality Of Work Life dan Kepemimpinan transformasional maka kinerja karyawan akan mengalami peningkatan.

\section{SIMPULAN}

Budaya organisasi berpengaruh positif dan signifikan terhadap kinerja karyawan PT. Harum Indah Sari (HIS) Tours \& Travel Bali. Hal ini berarti semakin kuat budaya organisasi, maka akan meningkatkan kinerja karyawan. Quality Of Work Life berpengaruh positif dan signifikan terhadap kinerja karyawan PT. Harum Indah Sari (HIS) Tours \& Travel Bali . Hal ini berarti semakin tingginya Quality Of Work Life, maka akan meningkatkan Kinerja karyawan. Kepemimpinan transformasional berpengaruh positif dan signifikan terhadap kinerja karyawan PT. Harum Indah Sari (HIS) Tours \& Travel Bali.Hal ini berarti semakin tingginya Kepemimpinan transformasional, maka akan meningkatkan Kinerja karyawan.

Pihak manajemen PT. Harum Indah Sari (HIS) Tours \& Travel Bali harus tetap mempertahankan Budaya organisasi, Quality Of Work Life dan Kepemimpinan transformasional di dalam perusahaan agar karyawan merasa puas dan dapat berkomitmen terhadap perusahaan, sehingga akan meningkatkan kinerja karyawan sesuai dengan target yang diinginkan oleh PT. Harum Indah Sari (HIS) Tours \& Travel Bali. Indikator yang memiliki rata-rata terendah dari variabel budaya organisasi adalah perusahaan memiliki standar perilaku yang serta standar pekerjaan yang pasti untuk saya terapkan. Dari indikator tersebut pihak perusahaan sebaiknya memberikan standar perilaku serta standar pekerjaan yang pasti untuk karyawan agar diterapkan dalam perusahaan, seperti mengadakan meeting rutin,sehingga karyawan merasa semangat dalam bekerja. Indikator yang memiliki rata-rata terendah dari variabel Quality of Work Life adalah para karyawan mampu menunjukkan kerja sama dalam tim. Dari indikator tersebut hal yang dapat dilakukan adalah dengan meningkatkan kerja sama tim serta hubungan satu sama lain diantara karyawan agar karyawan merasa nyaman saat bekerja sehingga kinerja karyawan semakin meningkat. Indikator yang memiliki ratarata terendah dari variabel kepemimpinan transformasional adalah pemimpin saya selalu menanamkan rasa kepercayaan diri yang kuat. Dari indikator tersebut hal yang dapat dilakukan adalah perusahaan harus meningkatkan kepemimpinan yang dapat menanamkan rasa kepercayaan diri yang kuat dan memotivasi karyawan, sehingga berdampak positif bagi perusahaan, dan karyawan menjadi termotivasi untuk mempertahankan kinerjanya. 


\section{REFERENSI}

Achmad Sobirin. (2007). Budaya: Sumber Kekuatan Sekaligus Kelemahan Organisasi. Jurnal Siasat Bisnis, 7(1), 1-20.

Adewale, O. O., \& Anthonia, A. A. (2013). Impact of Organizational Culture on Human Resource Practices : A Study of Selected Nigerian Private Universities. 5(4), 115-133. https://doi.org/10.7441/joc.2013.04.07

Adinata, W. S. U. (2015). Pengaruh kepemimpinan transformasional, motivasi, dan budaya organisasi terhadap kinerja karyawan kjks bmt tamzis bandung. Jurnal Ekonomi, Bisnis \& Entrepreneurship, 9(2), 136-157.

Ahmed, S., \& Uddin, M. N. (2012). Job satisfaction of bankers and its impact in banking: A case study of Janata Bank. ASA University Review, 6(2), 95-102.

Anteja, I. G. N. A. P. (2014). Pengaruh Kepemimpinan, Komunikasi, Lingkungan Kerja terhadap Semangat Kerja Pegawai pada PT.ANGKASA PURA Divis Komersial. E-Jurnal Manajemen Universitas Udayana, 3(2), 1-12.

Arifin, H. M. (2015). The Influence of Competence, Motivation, and Organisational Culture to High School Teacher Job Satisfaction and Performance. 8(1), 38-45. https://doi.org/10.5539/ies.v8n1p38

Aswin, Angga Erly., \& Rahyuda, A. . (2017). Pengaruh Perceived Organizational Support Terhadap Organizational Citizenship Behavior Dengan Variabel Kepuasan Kerja Sebagai Mediasi. . E-Jurnal Manajemen Unud, 6(5), 2729_ 2755.

Belias, D., \& Koustelios, A. (2014). International Review of Management and Marketing. Organizational Culture and Job Satisfaction: A Review, 4(2), $132-149$.

Bin, A. S., \& Shmailan. (2016). The relationship between job satisfaction, job performance and employee engagement: An explorative study. Issues in Business Management and Economics Journal, 4(1), 1-8.

Bindi, K. R., \& Dharmaraj, A. (2017). Quality of Work Life and Employee Performance in Academia. 3(May), 29-32. https://doi.org/10.9756/IJRAS.8154

Caillier, J. G. (2015). Public Personnel Management. December. https://doi.org/10.1177/0091026014528478

Cancerina, Y. (2013). Pengaruh Disiplin Kerja, Motivasi Finansial dan Budaya Organisasi Terhadap Prestasi Kerja Karyawan Pada CV. SINEZ. E-Jurnal Manajemen Unud, 2(12), 1662-1681. 
Caroline, O., and S. (2014). Influence of career Development on Employee Performance in The Public University. International Journal of Sciences Management and Entrepreneurship, 1(2), 1-16.

Chanana, M., \& Kumar Gupta, S. (2016). Quality of Work Life and Its Impact on Job Performance: A Study of S.B.I \& HDFC Banking Professionals. International Research Journal of Management, IT \& Social Sciences, 3(5), 16-24. https://doi.org/10.21744/irjmis.v3i5.12

Cheung, M. F. (2013). The Mediating Role Of Perceived Organizational Support In The Effect Of Interpersonal And Informational Justice On Organizational Citizenship Behavior. Leadership \& Organization Development Journal, 34(6), 551-572.

Cropanzano, Russel., \& Mitchell, M. S. (2005). Social Exchange Theory : An Interdisciplinary Review. Journal of Management, 31(6), 874-900.

Edison, Emron, Anwar, Yohni dan Komariyah, I. (2016). Manajemen Sumber Daya Manusia.

Edy Sutrisno. (2011). Budaya Organisasi.

Fung, N.S., Aminah Ahmad., \& Omar, Z. (2012). Work-Family Eanrichment: It's Mediating Role in the Relationships between Dispositional Factors and Job Satisfaction. International Journal of Academic Research in Business and Social Sciences, 2(11), 73-88.

Gultom, D. K. (2014). Pengaruh Budaya Organisasi Perusahaan Dan Motivasi Terhadap Kinerja Karyawan Pada Pt. Perusahaan Gas Negara (Persero) Tbk Medan. Jurnal Manajemen \& Bisnis, 14(02), 1693-7619.

Gupta, N., Sharma, V. (2016). Exploring employee engagement-a way to better business performance. Global Business Review, 17, 45S-63S.

Gupta, A. (2013). No Title Relationship Between Enrrepreneuirial Personality Between Entrepreneurial Personality, Job Satisfaction and Operations Strategy An Empricial Examiniation. International Journal of Business and Management, 8(2), 387-393.

Hande Serim, Orkum Demirbag, U. Y. (2014). The effect of employee perceptions of competency models on employability outcomes and organizational citizenship behavior and the moderating role of social exchange in this effect. International Strategic Journal, 150, 1101-1110.

Hardinaya, Iskandar, S., Nurlaila, I. (2013). Pengaruh Budaya Organisasi Dan 
Kompensasi Terhadap Motivasi Kerja Serta Implikasinya Terhadap Kinerja Guru. Jurnal Ekonomi, Bisnis \& Entrepreneurship, 7(2), 64-73.

Harwiki, W. (2016). The Impact Of Servant Leadership On Organization Culture, Organizational Commitment, Organizational Citizenship Behaviour (OCB)

And Employee Performance In Women Cooperatives. Procedia - Social and Behavioral Sciences, 219, 283-290.

Irawati. (2015). PENGARUH KUALITAS KEHIDUPAN KERJA SAMPANG. Jurnal Neo-bis. 9(2), 41-52.

Ibrahim, Ali.M., \& Ahmed, A. S. A. (2013). The Impact Of Organizational Culture on Employees Performance of Mogadishu Universities. Academic Research International, 4(2), 382-390.

Irwan Sugiarto. (2018). Pengaruh Budaya Organisasi dan Motivasi Kerja Terhadap Kepuasan Kerja serta Implikasinya Terhadap Kinerja Karyawan. Banking and Management Review, 2(1), 125.

Istri,H.,P.,Putri \& Iskandar, D. (2016). Pengaruh Gaya Kepemimpinan Transformasional Terhadap Kinerja (Studi kasus pada PT Bank Rakyat Indonesia (Persero) tbk kantor cabang Nagwi Jawa Timur). Eproceeding Of Management, 3(2), 1086-1095.

Jia, L., Shaw, J.D., Tsui, A. S \& Park, T. Y. (2014). A social- structural Perspective on employee organization relationships and team creativity. Academy of Management Journal, 57(3), 869-891.

Maith, V. (2015). nalisa Pendidikan, Motivasi dan Budaya Organisasi Terhadap Kinerja Karyawan Pada Gerbang Nusa Mando. Jurnal Berkala Ilmiah Efisiensi, 15(5), 667-776.

Majumdar, Malini Nandi; Dawn, Debosmita \& Dutta, A. (2012). Impact Of Quality WorkLife On Job Performance: A Case Study On Indian Telecom Sector. International Journal of Arts \&Sciences, 5, 655-685.

Matei, C. S. (2015). Organizational Culture and Creativity's Perspectives, Euromentor Journal Studies About Education. Journal Studies, 7(3), 40-47.

Miharty Miharty. (2013). The Influence of Organizational Culture on Job Satisfaction towards Improving the Quality of Education in University of Riau. Asian Social Science, 9(12), 231.

Muhammad Ibrahim Khan's, Shahzad Muhammad Yasir, U. A. (2012). RANSFORMATIONAL LEADERSHIP, EMOTIONAL INTELLIGENCE AND ORGANIZATIONAL COMMITMENT: PAKISTAN'S SERVICES 
SECTOR. International Journal of Management and Strategy, 33(2), 67-92.

Nanjundeswawary, S. (2013). Quality Of Worklife of employees in private technical institutions. International Journal for Quality Research, 7(3), 3-14.

Nata Wirawan. (2015). Cara Mudah Memahami Statistika.

Ni Luh Putu Ariesta Angga Dewi, I. W. M. U. (2016). PENGARUH PENGEMBANGAN KARIR TERHADAP KINERJA KARYAWAN MELALUI MEDIASI MOTIVASI KERJA PADA KARYA MAS ART GALLERY. E-Jurnal Manajemen Universitas Udayana, 5(9), 5494-5523.

Ni Putu Melda Cahaya Santhi. (2016). PENGARUH QUALITY OF WORK LIFE, DAN MOTIVASI TERHADAP KEPUASAN KERJA KARYAWAN. E-Jurnal Manajemen Universitas Udayana, 5(11), 7300-7327.

Northhouse, P. G. (2013). Leadership: Theory and Practice.

Pasaribu, E. K., \& Indrawati, A. D. (2016). KERJA TERHADAP KINERJA PEGAWAI DINAS SOSIAL PROVINSI BALI Fakultas Ekonomi dan Bisnis Universitas Udayana (Unud), Bali, Indonesia PENDAHULUAN Tumbuh dan berkembangnya suatu organisasi tergantung pada sumber daya manusia . Maka dari itu organisasi harus. 5(12), 7785-7809.

Permana, DA., Hamid, D dan Iqbal, M. (2015). Pengaruh kualitas kehidupan kerja dan lingkungan kerja terhadap disiplin kerja (studi pada karyawan PT. Bank Negara Indonesia (persero) kantor cabang utama malang. Jurnal Administrasi Bisnis, 26(2), 1-10.

Pors, N. O. (2008). Management Tools, Organizational Culture and Leadership an Explorative Study. Journal Performance Measurement and Metrics, 9(2), 138-152.

Pradana, M. A. (2013). Pengaruh Kepemimpinan transformasional dan Transaksional Terhadap Kinerja Karyawan Tetap PT. Mustika Bahana Jaya, Lumajang. Jurnal Administrasi Bisnis, 4(1), 1-11.

Pratiwi, K., \& Himam, F. (2014). Kualitas kehidupan kerja ditinjau dari kepuasan kerja dan persepsi terhadap kinerja. 13(1), 42-49.

Rahmawati, T. K. (2017). The Influence of Quality of Work Life and Organizational Culture on Employee Performance with Job Satisfaction as an Intervening Variable. 1-13.

Rahmi, B. M. (2014). Pengaruh Kepemimpinan Transformasional Terhadap Organizational Citizenship Behavior dan Komitmen Organisasi Dengan 
Ni Putu Pratiwi Irmayanthi, Pengaruh Budaya Organisasi...

Mediasi Kepuasan Kerja. E-Jurnal Manajemen Universitas Udayana, 3(2), 330-350.

Rai, R. (2015). A Study on QWL and its effects on Job Performance. 2(2), 33-42.

Ramezan, M. (2016). Examining the Impact of Organizational Culture on Social Capital in a Research Based Organizations. Journal of Information and Knowledge Management Systems, 46(3), 411-426.

Rolasmana. Meza. (2013). Pengaruh Gaya Kepemimpinan, Efektivitas Pengambilan Keputusan, dan Pemberian Kompensasi Insentif terhadap Kinerja Karyawan Bagian Keuangan pada Swalayan di Tanjungpinang. Jurnal. Tanjung Pinang: Universitas Maritim.

Sagita, A.A Susilo, H., \& W.S, M. . (2018). Pengaruh Budaya Organisasi Terhadap Kinerja Karyawan dengan Motivasi Kerja Sebagai variabel Mediator. Jurnal Administrasi Bisnis, 57(1), 2357-2747.

Septyan, F. B., Musadieq, M. Al, Mukzam, M. D., Administrasi, F. I., \& Brawijaya, U. (2017). MOTIVASI DAN KINERJA ( Studi Pada Karyawan CV . Jade Indopratama Malang ). 53(1), 81-88.

Sinaga, H. G., Asmawi, M., Madhakomala, R., \& Suratman, A. (2018). Effect of Change in Management, Organizational Culture and Transformational Leadership on Employee Performance PT . Adhya Tirta Batam. 8(6), 15-23.

Sudibya, I. K. A. D. I. G. A. (2019). PENGARUH KEPEMIMPINAN TRANSAKSIONAL, BUDAYA ORGANISASI, DAN KOMUNIKASI TERHADAP KINERJA KARYAWAN. E-Jurnal Manajemen Universitas Udayana, 8(9), 5847-5866.

Sutanto, E. M., M. K. (2016). The impact of recruitment, employee retention and labor relations to employee performance on batik industry in Solo City. International Journal of Business and Society, 17(103).

Tinofirei C. (2011). The Unique Factors Affecting Employee Performance in non profit Organization.

Wanjiku, N. A., \& Lumwagi, N. (2014). Effect of Organisation Culture on Employee Performance in Non Govermental Organizations. International Journal of Scientific and Research Publications, 4(11), 112.

Widodo, W. (2014). Upaya peningkatan kinerja inovatif berbasis pola cerdas dalam konteks teknologi informasi. Journal of Technology Management, 13(2), 154-172.

Yu, B. (2013). The Influence Study of Transformational Leadership in University 
on Teachers' Organizational Commitment: The Construction and Verification of a Theoretical Model. Canadian Social Science Journal Verification of a Theoretical Model, 9(4), 126-137.

Zameer, Hashim, Shehzad Ali, W. N. and M. A. (2014). The impact of the motivation on the employee's performance in beverage industry of pakistan. Journal of Academic Research in Accounting, Finance and Management, Science, 4(1), 293-298.

Zeinabadi, Hassanreza and Salehi, K. (2011). Role Of Procedural Justice, Trust, Job Satisfaction, and Organizational Commitment in Organizational Citizenship Behavior (OCB) of Teachers: Proposing A Modified Social Exchange Model. Procedia - Social and Behavioral Sciences, 29(2), 1472 1481. 